\title{
A Secure News Web-Based Application for Multiple users Sharing Information Publically
}

\author{
Muhammad Aamir Panhwar', Sijjad Ali khuhro², Kamran Ali Memon', \\ Pervaiz Ahmed ${ }^{3}$ and Saleemullah Memon ${ }^{4}$ \\ 'School of Electronic Engineering, Beijing University of Posts and Telecommunications, China; \\ maamirpanhwar@gmail.com, ali.kamran77@gmail.com \\ ${ }^{2}$ School of Computer Science and Technology, University of Science and Technology of China, Hefei, \\ China; Sijjadali786@mail.ustc.edu.cn \\ ${ }^{3}$ Institute of Information Technology, Quaid-i-Azam University, Islamabad, Pakistan; Pervaizthul1@gmail.com \\ ${ }^{4}$ School of Information and Communication Engineering, Beijing University of Posts and \\ Telecommunications, China; saleem@bupt.edu.cn
}

\begin{abstract}
Objectives: To develop a secure web application for geographic collection of news through ordinary users of intends and geographic based viewing system of the news. Users of our web application, News can view of their own choice of geographic area. Methods/Statistical Analysis: We analysis and developed our web application in ASP.NET by using C\# language, Moreover, we tested all phases carefully of our web application. Findings: There are different ways to publish or broadcast news from newspaper, radio, television etc. They all employ different mechanism to collect news items. The system development use intended mechanism for publishing of news contents but use a different way of collecting news items and different way of viewing those collected news contents. Application improvement: Our News web application discussed in this article is a very worthwhile web based application that provides news of the world. This application allows users to read according to their news profile. By using this web application user get news of their environment or world to become update from their environment.
\end{abstract}

Keywords: Database, Secure, System Interfaces and Modeling, Web application

\section{Introduction}

Now a day's web based technology developed in every field of sector such as IT sectors, Health sectors, News sectors and many more ${ }^{1}$. But this is the age of science and information and we cannot remain far from what is happening around us. To keep ourselves updated of latest political and social happening, we need to be update by the news.

The world has become into a global village and it is impossible to develop without knowing about political and social developments in the form of the news. The news enables us to decide in a better way when it comes to making decisions. Now the problem is how to be update by news of our environment, there are many ways to update ourselves by news like using modern technologies (websites). Our News is a web application that provide news of our environment similar web applications are www.facebook.com and www.twitter.com both application provides different type of news and have many purposes, but our News web application has single purpose to update people by news of their environment and this application provides a golden chance to share news, information, or knowledge to update the people of the world.

Facebook is a popular free social website that allows users to create profiles, upload photos and video, send 
messages and keep in touch with friends. Facebook offers a range of privacy options to its members. A member can make all his communications visible to everyone, he/she can block specific connections or he /she can keep all his communications private. Members can choose whether or not to be searchable, decide which parts of their profile are public, decide what not to put in their newsfeed and determine exactly who can see their posts. For those members who wish to use Facebook to communicate privately.

Twitter is an online social networking and microblogging service that enables users to send and read "tweets", which are text messages limited to 140 characters. Registered users can read and post tweets, but unregistered users can only read them. Users access Twitter through the website interface, SMS, or mobile device app. Tweets are publicly visible by default, but senders can restrict message delivery to just their followers.

Our News is web based application that provides facilities to upload and view classified news according to their news profile, all news are public that everyone can read news. Our News web application provides right, correct, and updated news. To make updated our News web application it is not practice of any single user so our News web application has many users that will update, verify, or block news. Uploaded news will be visible for everyone there is no restriction that any user cannot read or view news. News web application's purpose is to update people by news of their environment according to their news profile there is no privacy of news that any user cannot read or view news any user can read/view news that are uploaded, no one user can hide news from any user.

Construction of our article follows as: Section 2: Comparison of our news web based application with others applications. Section 3: System Design. Section 4: System Functionalities. Section 5: Implementation phase. Section 6: Testing Phase. Section 7: Conclusion and Future Enhancement.

\section{Comparison of our News based app and Other Similar Web Applications}

The news of our web application has no privacy to hide from any user. Facebook user can hide any information from any user and only the user can see information of the user if they are friends and twitter that also provide privacy to user that user who sends tweets can restrict message delivery to just their followers if anyone who is not following anyone cannot read tweets. The users of our News web application can view news of their own choice of area but Facebook and twitter users have no facility to view news of their own choice area. Other newspaper websites like www.jung.com.pk, http://x.dawn.com/ provides news to read only but user cannot upload/share their news.

\section{System Design}

Design Phase of New web applications currently interaction with design we called it "glamorous" the way in which developers can create very innovative web-based applications ${ }^{2}$. Our News is web application that provides news as a publically. Users can upload and view news of classified area according to user's news profile, for the correctness purpose news will be verified and then will be visible for all users, for verification there is a user named trusted user that will verify news of their related area (Figure 1 shows flow of news). For uploading news user must be registered, for registration purpose user will create his/her account to upload news. The users can also configure their news profile to see classified news (news of their choice area). For the purpose of maintain system up to date there are different type's users who will maintain the system named unregistered users, registered users, trusted users, Sub Administrators and Administrators, they perform different roles in My Web application. Unregistered users are those users who can read news, can create account for registration and also they can set their news profile, Registered users can upload news and also they can read news and set their news profile, Trusted users verifies the uploaded news of their location and also can block the news that if news is incorrect. Verified news by trusted users will be visible for all users and Administrators or sub administrators who has all controls of our News web application like upload news, set news profile, verify news, can allow users to upload news without news verification, can block the users, assign responsibilities of trusted user to any user and also can remove the responsibly.

\subsection{Unregistered User}

Unregistered can set news profile to display news of particular area on his/her system and can dislike giving feedback that if news wrong, for registration they can also create account. 


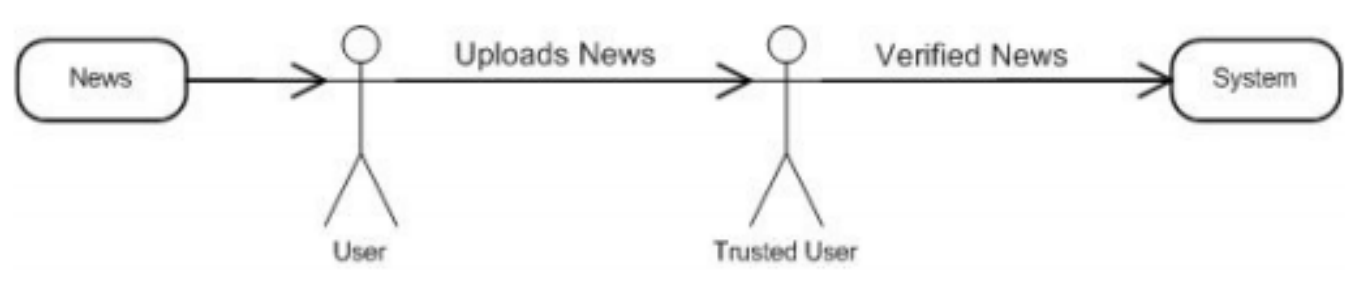

Figure 1. News flow chart.

\subsection{Registered User}

Registered users can upload news by providing required information about news after logged in, for login user provides username and password.

\subsection{Trusted User}

Trusted user will verify news of their areas and also can block news that are disliked by any user and also can upload news.

\subsection{Sub Administrator}

Sub-Administrator act as administrator but cannot make other sub-administrators, can assign responsibility of trusted user to any user and also can upload news.

\subsection{Administrator}

Assigns responsibilities of trusted user, sub administrator to any user, block news, block user to upload news.

\section{System Functionalities}

Use case describes system behavior under various conditions that how the system responds to the request from one of its stakeholders and it tells the story about how end user interacts with the system. In software and systems engineering, a use case is a list of steps, typically defining interactions between a role (known in Unified Modeling Language (UML) as an "actor") and a system, to achieve a goal ${ }^{3}$. The actor can be a human or an external system ${ }^{4}$.

- News Profile: User set news profile to view news of specific location/area by selecting location/ area

- Dislike News: User can dislike any news if users feel that news is wrong.
- Create Account: User can create account to be registered to use privileges of registered user.

- Login: To login user must be registered to use given privileges.

- Upload News: Any user who is registered after login he/she can upload news.

- Verify News: News will be verified by trusted user and administrator to control wrong news.

- Block News: The news disliked by any user can be blocked by trusted user or administrator.

- Block User: The user who uploads news again and again which disturbs the system and users can be blocked by administrator.

- Make user as trusted: Administrator can assign responsibility to any user for verification of news and speed up system.

- Make user as sub administrator: Administrator can assign responsibility to any user to share own responsibilities to speed up system.

\subsection{User System Interaction}

The users interact with our News web application easily to upload news, read news, dislike news, creates account or login. The unregistered users can read news, set their news profile, dislike wrong news and also they can create their account to be registered user of My News web application after the creating account user will be registered and then user can upload news, another registered user who two responsibilities by administrator called trusted user can verify or block news to control wrong news, another registered user has responsibilities assigned by administrator to speed up the system can perform all responsibilities of administrator except assigning responsibility of sub administrator. The administrator has all privileges to make user as sub administrator, trusted user or to block news or user and administrator an allow any user to upload news without news verification and if any 
user is already allowed to upload news without verification administrator can disallowed to user uploading news without news verification. Figure 2 shows user system interaction with web application.

\subsection{System Components}

- Account Creation: User provides required information to create account and the system will check that all required information is provided if any requirement is missed or not provided then system response to show message that "please fill fields" or all required information is provided then system will check that, if user is already registered then system will response to show message that "you are already registered" or user is not already registered then system will send email to provided email address for user's email id verification and response to user that "email sent to your email address please go to inbox and verify email address to create account", when email id is verified system will show account information and then user can login to use privileges of registered user. More details follow in Figures 3(a) \& 3(b).

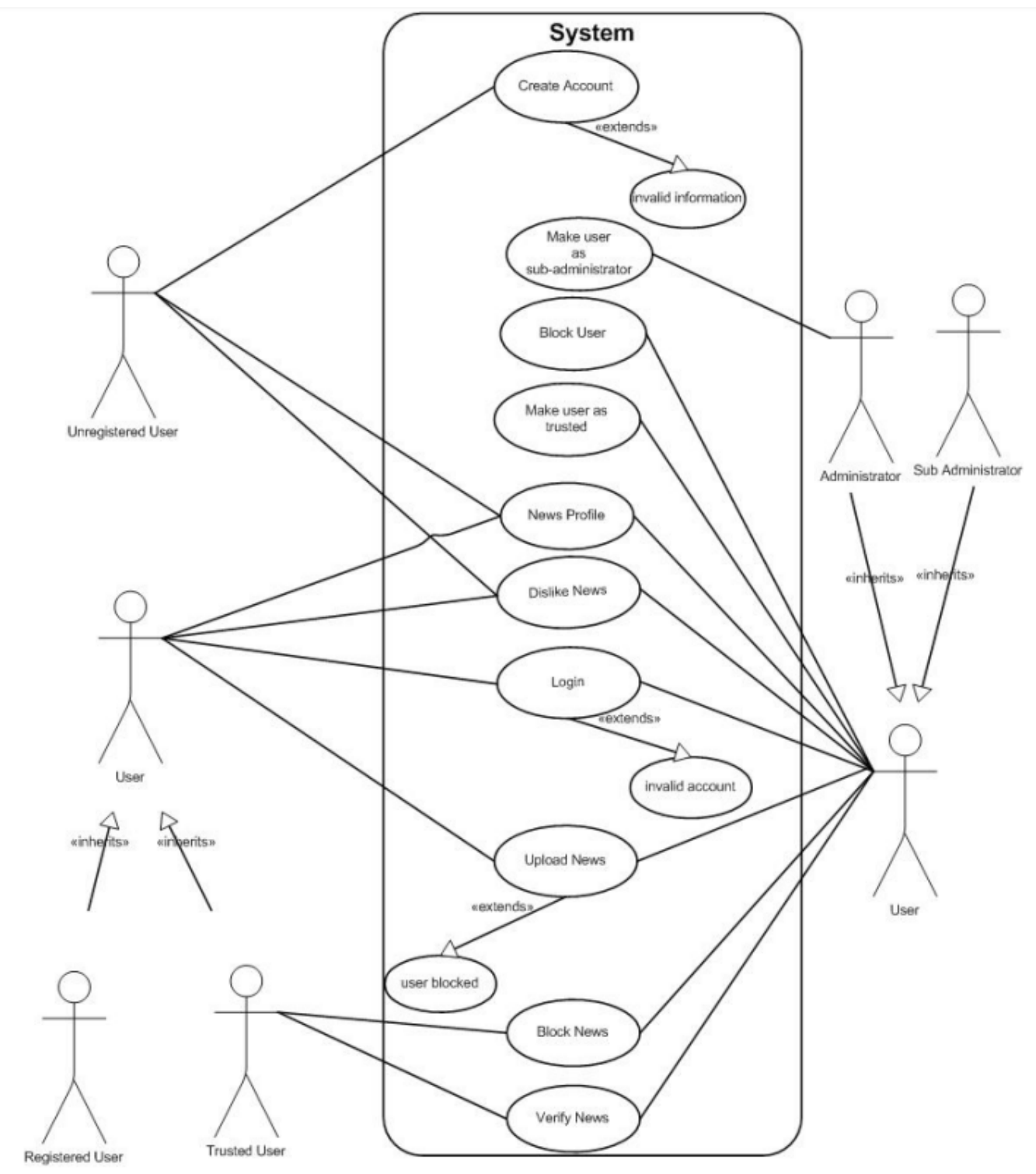

Figure 2. User system interaction. 


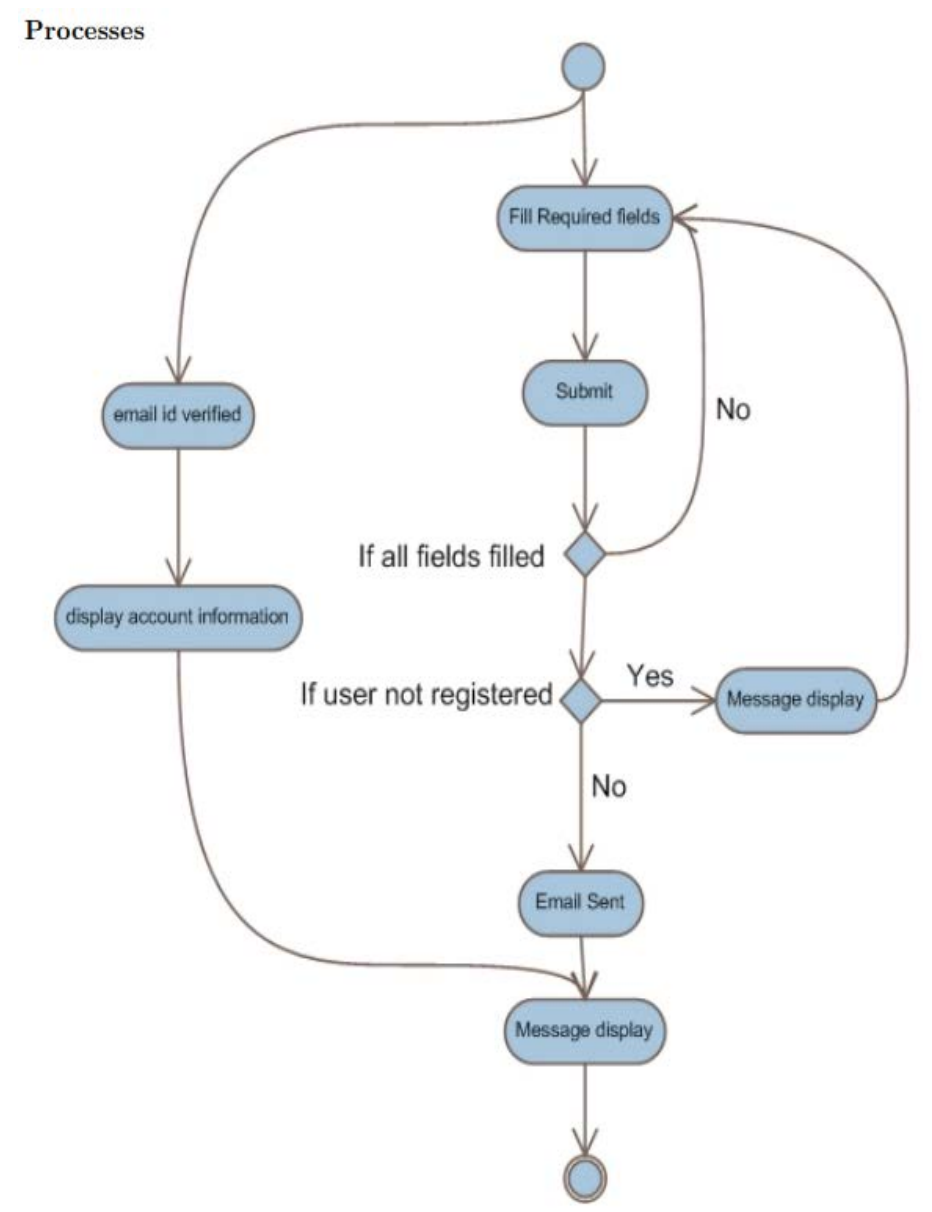

(a)

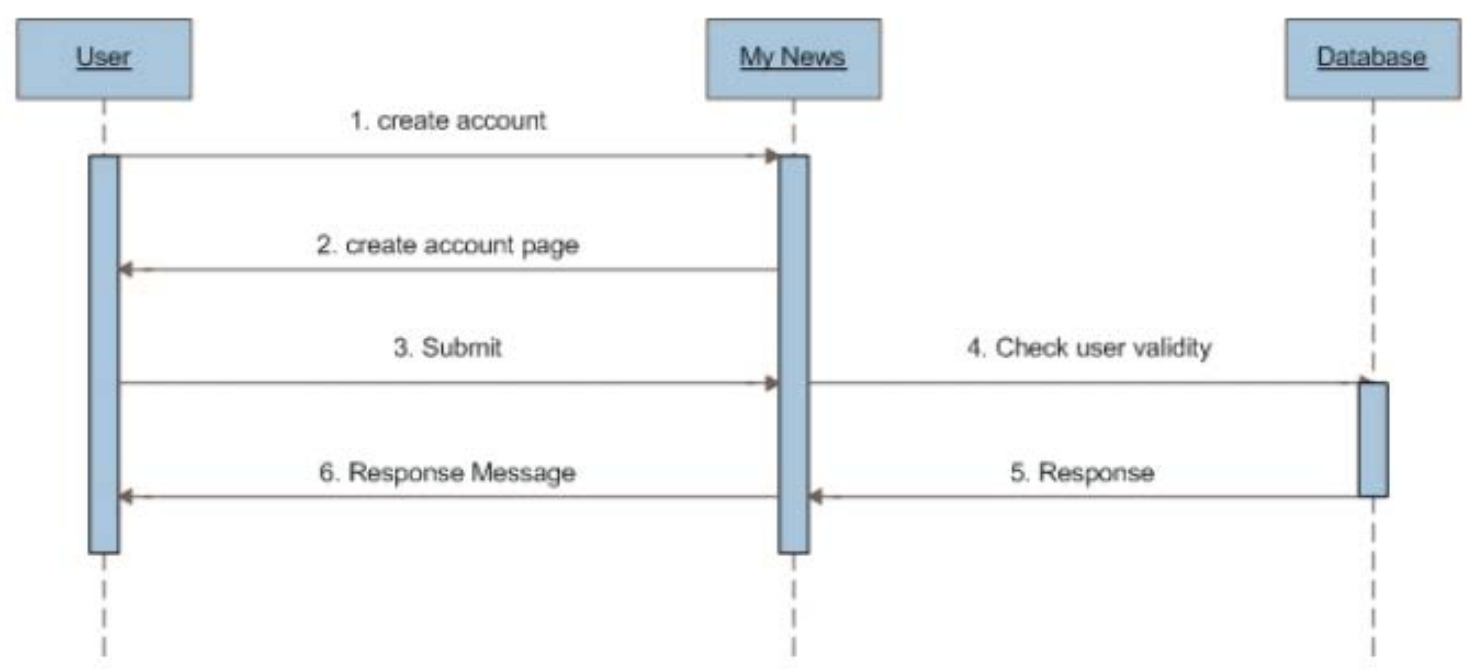

(b)

Figure 3. (a) Account creation. (b) Account creation. 


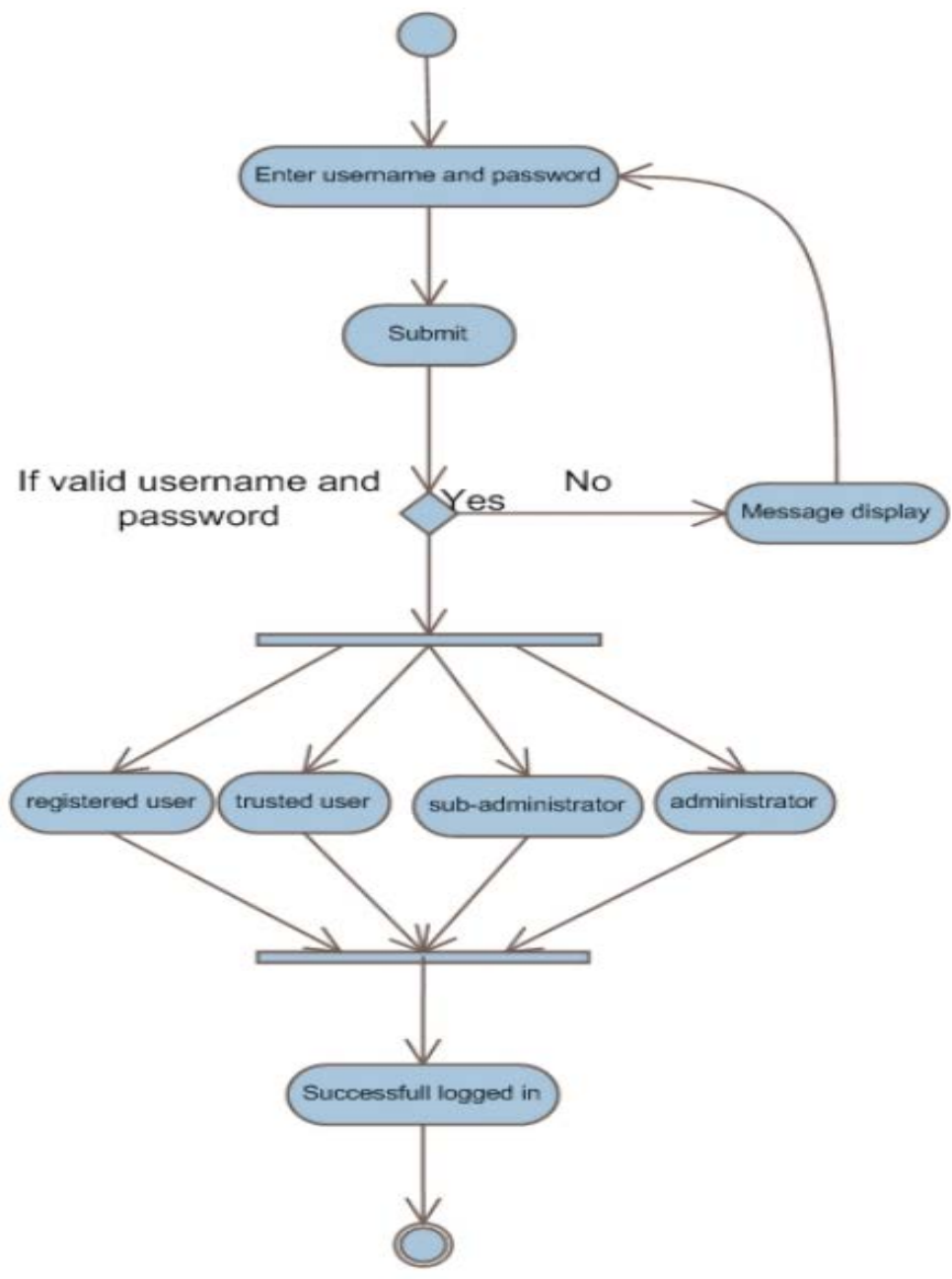

(a)

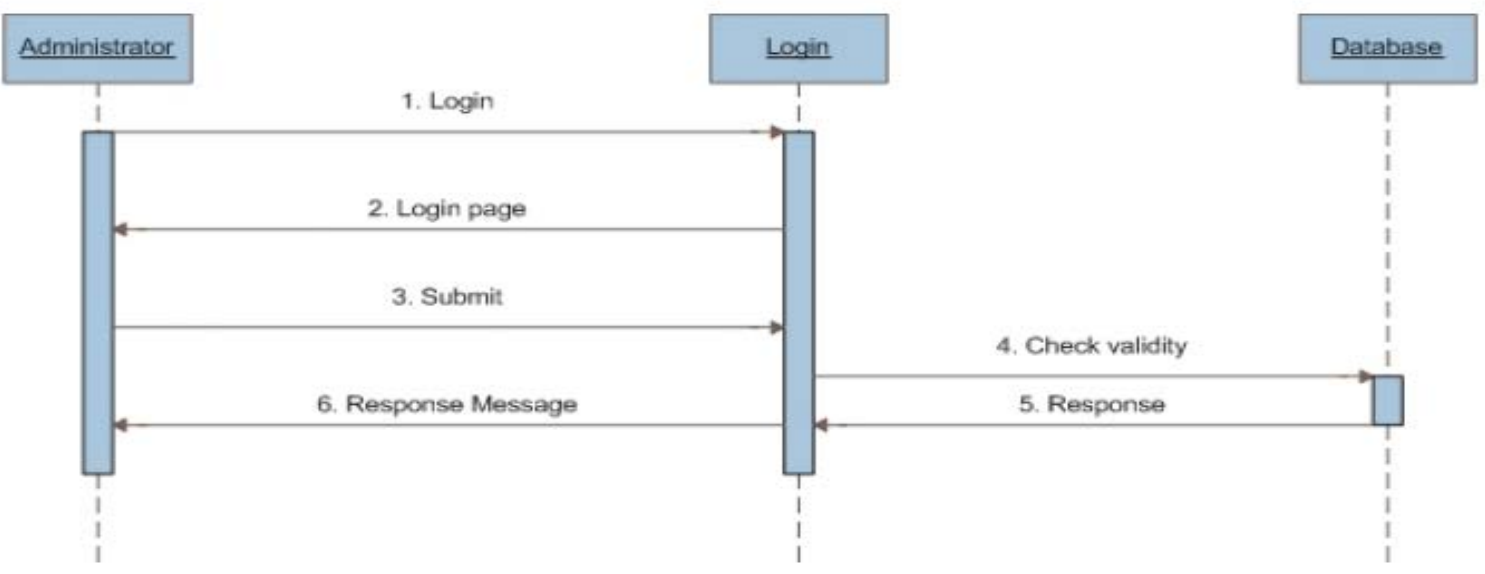

Figure 4. (a) Access of provided privileges. (b) Access of provided privileges. 
- Accessing Provided Privileges: Any user can access by providing username and password system will check the username and password, if user is not registered system will show message that "username or password is invalid" or user is registered, then system will check user has what type of privileges like administrator, subadministrator, trusted or registered then system will provide the access of privileges that user has, which are detailed in Figures 4(a) \& 4(b).

- Retrieving Forgotten Password: The user who forgotten password can retrieve his/her password by providing security information (security question and answer) that is provided during the account creation then retrieve the password by information provided and system will check that the answer, if answer is wrong the system will show message provided answer is wrong you cannot retrieve password please provide right answer, detailed in Figure 5. If answer is right the system will the password to the provided email address and show message that your password is retrieved please check your email inbox.

- Submitting/Uploading News: Any user who has account of our news web application can upload news, except blocked user to upload news must be logged in and provide news title, news detail and picture (optional) and upload it after uploading news system will check that all necessary information is provided by user, if any information is missed system will show message that "Please fill all fields to upload news" or all necessary information is provide (news title and news detail) then system will check that user is not blocked if user is blocked to upload news then system will show message that "You cannot upload news because you are blocked by administrator" or user is not blocked then news will be verified by trusted user if trusted user disapprove the news then the news will be removed or

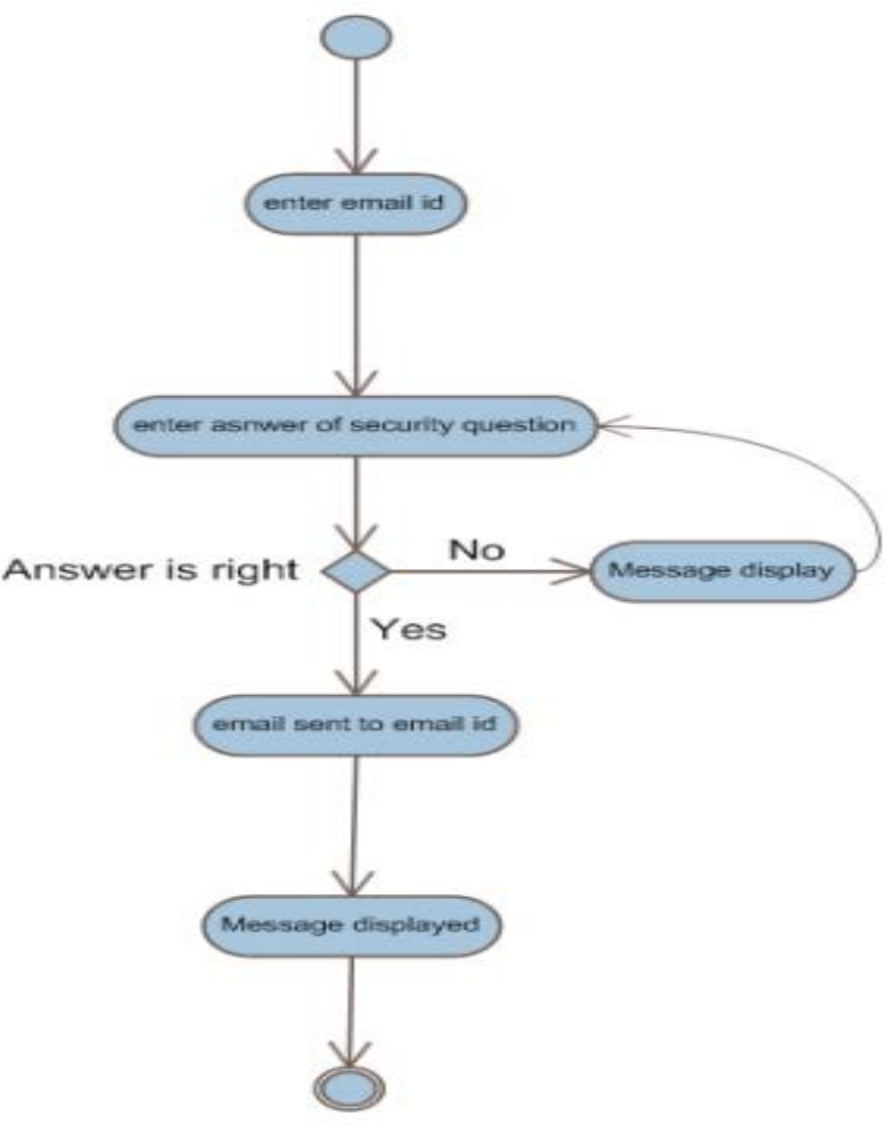

Figure 5. Retrieving password. 


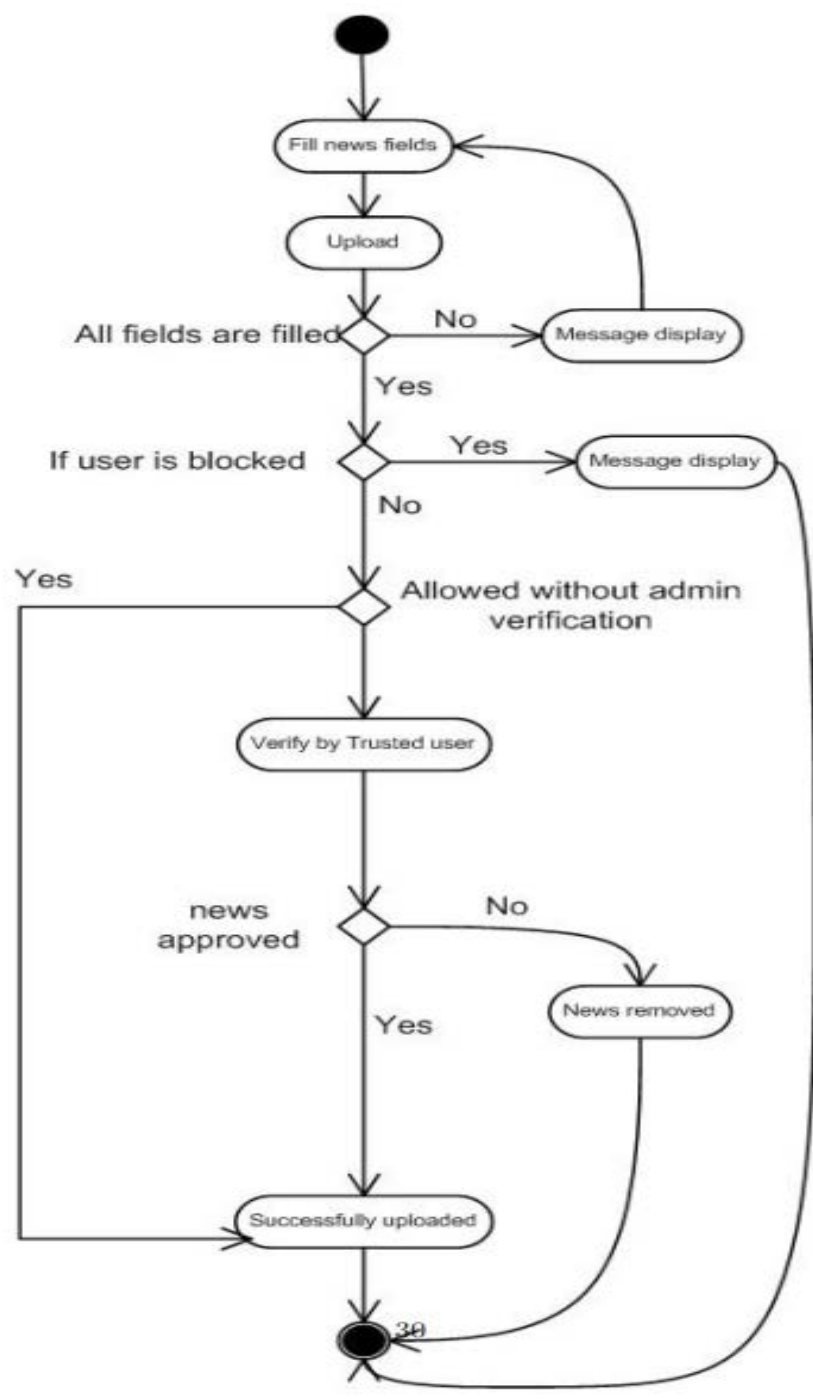

(a)

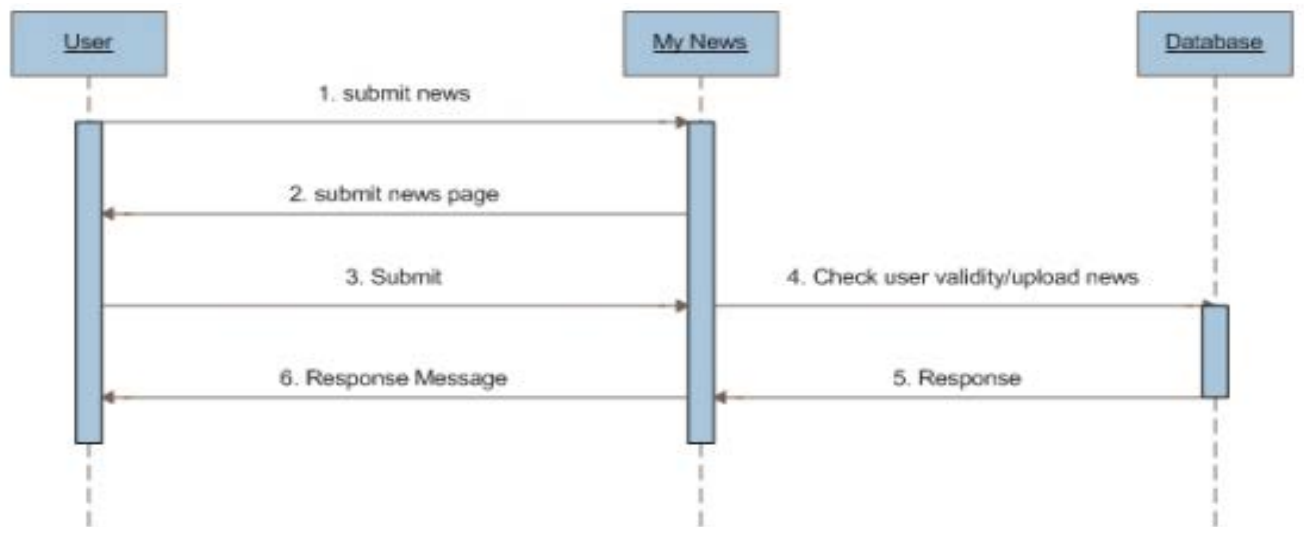

(b)

Figure 6. (a) Upload news. (b) Upload news. 
trusted user approve the news then system will check the user who uploaded news is allowed to upload news without administrator verification. if user is not allowed then the news will be verified by the trusted user if trusted user disapprove the news then the news will be removed or approve the news then the news will be displayed on the My news web application (details in Figures 6(a) \& 6(b)).

- Blocking News: Any user can upload news and dislike news the disliked news will displayed to trusted user, sub-administrator and administrator in separate content then news will be verified or blocked by any of them.

- Blocking User: The sub-administrator or administrator can block any user who uploads wrong news again and again by searching user by name, location or email id and can block him/her to upload news.

- Disliking News: Any user reads news and they know that news is wrong then they can give feedback that news is wrong by disliking.

- Setting Up News Profile: Any user can setup a news profile to show (Figure 7) news of specific location home of our News web application for his system by navigating to the news web application news profile page and selecting specific location are shown in Figure 8.

- Verifying News: Processes of news verification are described in uploading news. This process is happens when news uploads.
- Assigning Privileges of Trusted User: Subadministrator or Administrator can assign privileges of trusted user to any user by searching with name, location or by email id by their privileges content page.

- Assigning Privileges of Sub-Administrator: only administrator can assign privileges of subadministrator to any user by searching with name, location or email id by his/her privileges content page.

\section{Implementation Phase}

The most important purpose of implementation is to move design into computer executable software. Implementation locates the most recent software increment into the environment. In the implementation platform, programming language and development tools for the implementation are selected according to the requirements of the project. According to system design system is implemented. News web application is all about news and provides news to the users, but the registered users of News web application can upload news and that news will be right to upload to control the incorrect/wrong news to display Trusted user will verify that news is right/correct to display on News web application. For the purpose of updated, correct news there are different type of users will verify, upload news or block news. Unregistered user creates an account for registration and few registered are given responsibilities by administrator.

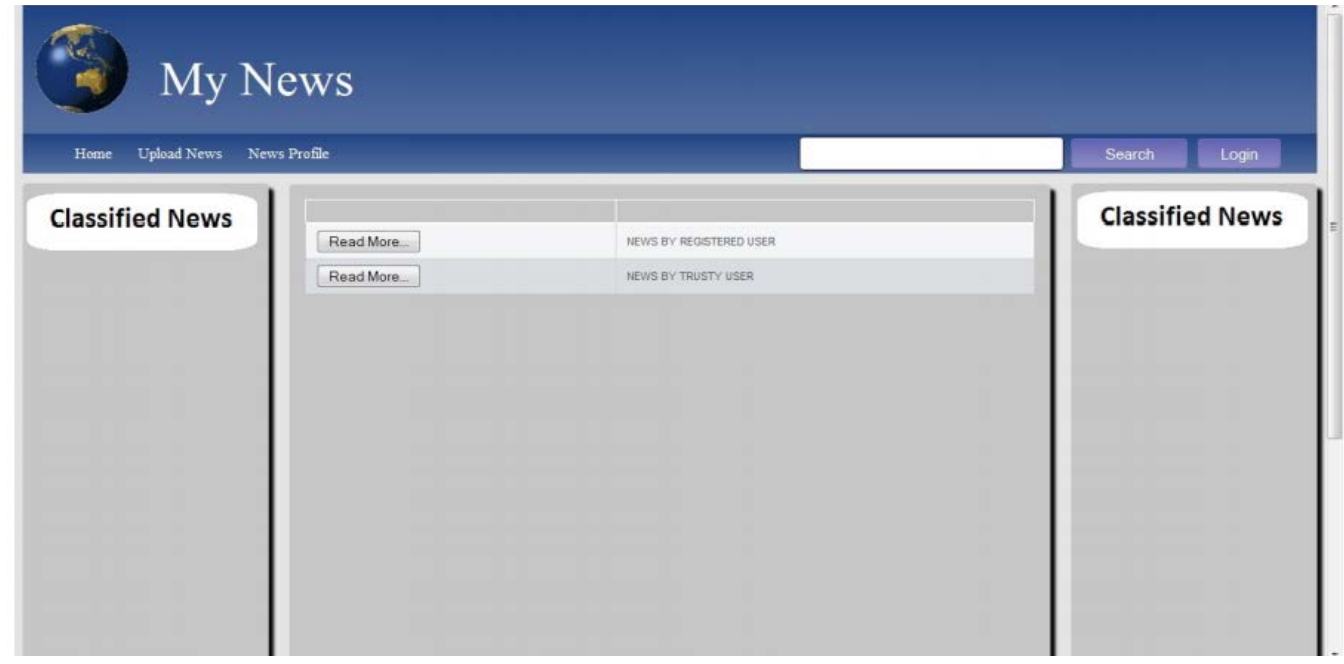

Figure 7. Homepage. 


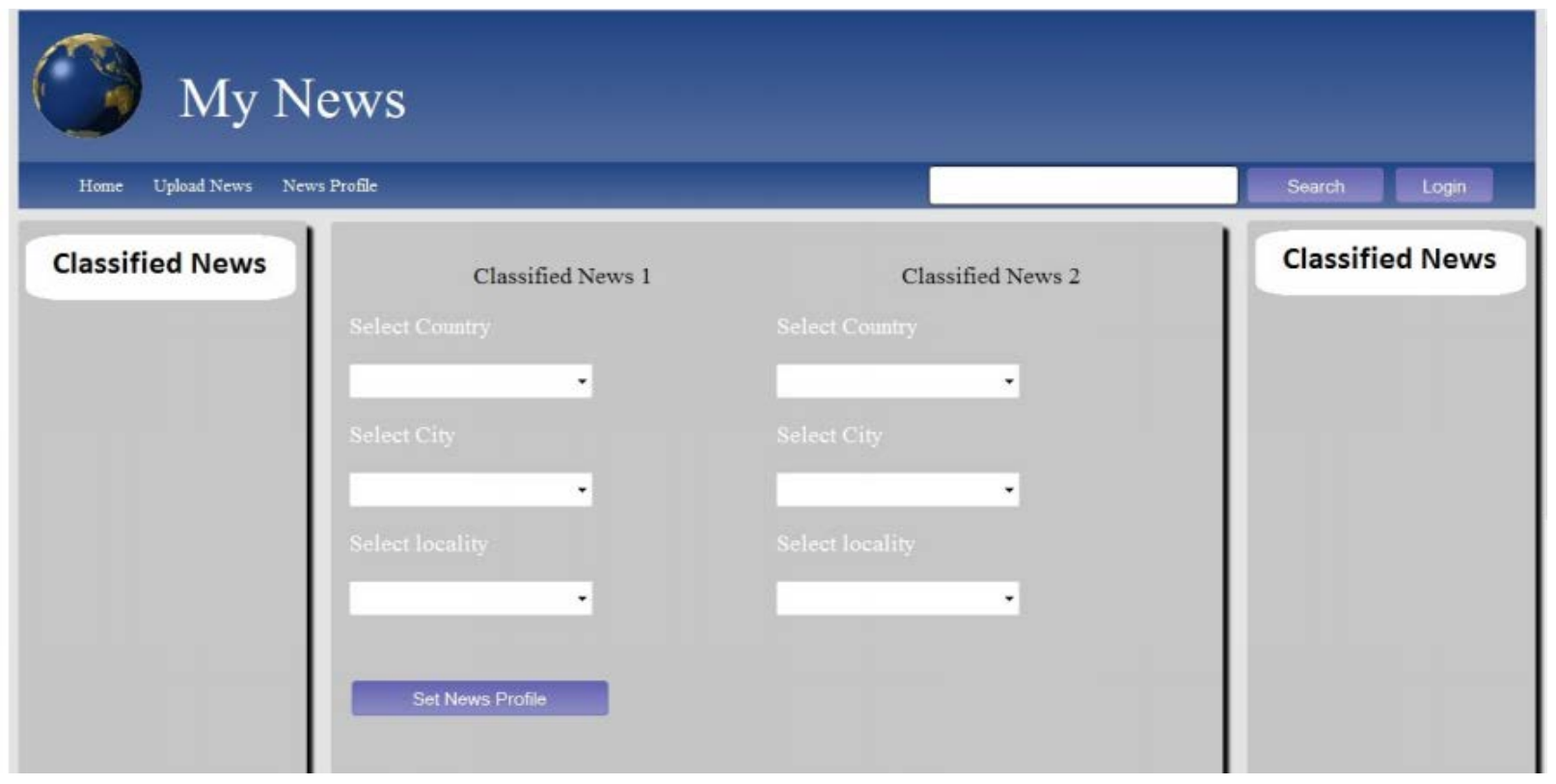

Figure 8. News Profile.

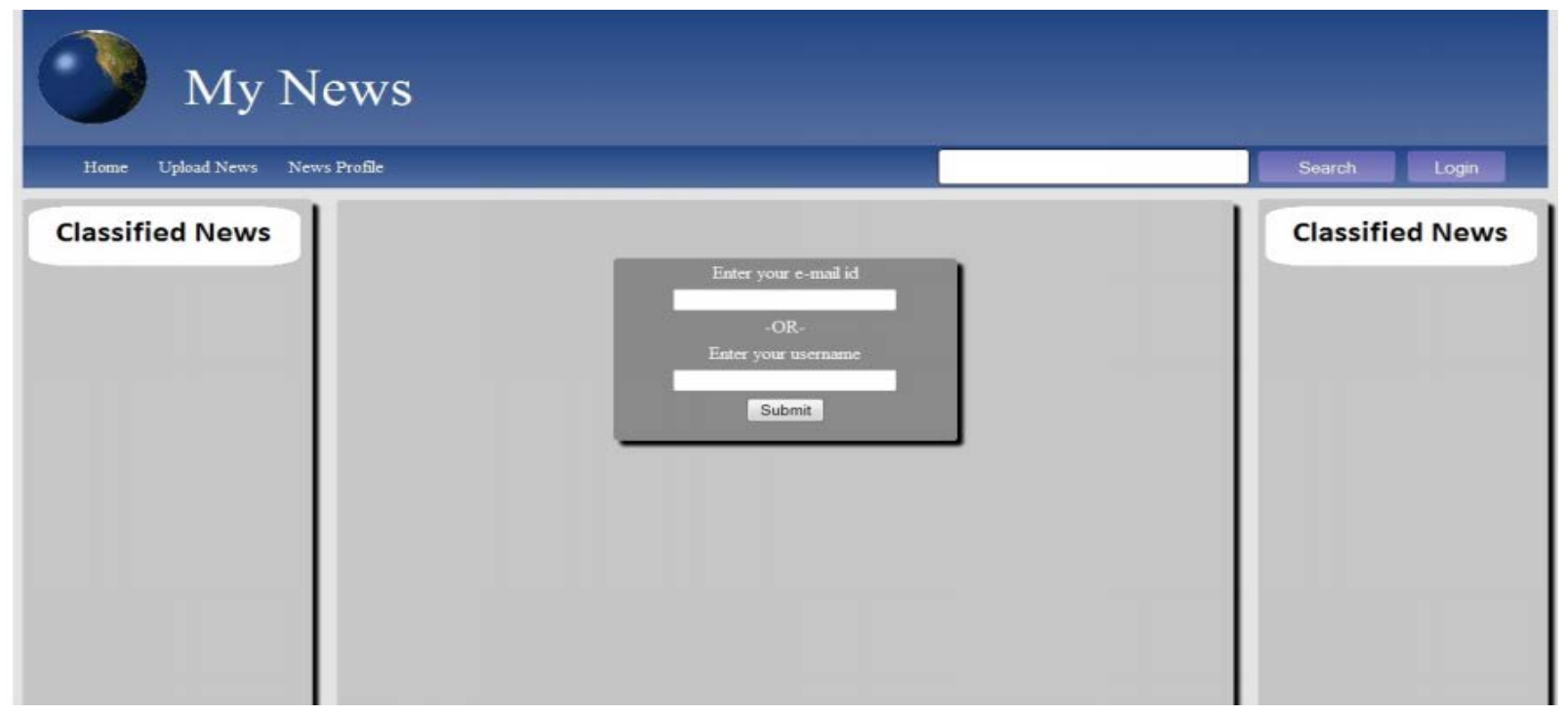

Figure 9. Retrieve forgotten password page.

- User Information: All data about user is stored the attributes of user reg_id is store user's registration id, name is to store name of the user, username is to store username of the user for login, email_id is to store email id, password is to password, country is store country name of the user, city is to store city name of the user, locality is to store locality of the user, security question is to store security question for retrieving forgotten password, are shown in Figure 9, answer is to store answer of the security question, status is to store status (blocked or unblocked) of user , authority is to store authority (privileges i.e., trusted user or administrator), admin_permission is store administrator's permission to the user to upload news without verification.

- News information: Data is stored all about news the attributes news_id to store news id, news_ title to store news title, news_detail to store news detail, picture to store picture name, user- 
name to store username who uploaded news, upload_time to store date and time when news is uploaded, user_feedback to store number of dislikes of news, block store data that news is blocked, cmnt_id to store foreign key, primary key of comments table, country to store country name form where news is uploaded, city to store city name from where news is uploaded, locality to store locality from where news is uploaded, news_rate to store number of how much news is viewed, trusted_verified to store information that news is verified by trusted user and key_ words for searching news.

- Administrator Comments: Comments again any news are given by administrator are stored attributes are used to comt_id is to store comment and comment is to store comments description data.

- Countries and Cities: Country names and their cities are stored attributes country_id to store comment ids, city_name is to store city names and country_name is to store country names are used to store data. Any news is disliked by any user will be verified again by trusted user, subadministrator or administrator to block is tested to ensure to after blocking of news any user has privilege to block news is being blocked.

\section{Testing Phase}

The real importance of testing is to ensure better quality of assurance, verification or reliability estimation so that problems can be found and also to find the problems which to be got it fixed. Testing is a way of analyzing a software item to know the difference between existing and required conditions and the features of the software item. It attempts to make things go wrong to know if things happen when they shouldn't or thing don't happen when they should 5 .

- Testing has basically four purposes:

- Fault identification: what fault caused the failure?

- Fault correction: change the system

- Fault removal: take out the fault

- Quality Improvements: Performing as required under specified circumstances the objective of testing is to uncover errors in the software and to validate software to the customer requirements.
- Software: For complete test activities tester need is (at minimum) Microsoft Windows 7 operating system, Internet Explorer 7 or higher.

- Hardware: For complete test activities tester needs (at minimum) a computer Pentium II 533 $\mathrm{MHz}, \mathrm{RAM} 128 \mathrm{Mb}$.

\subsection{Test Cases}

A test case, in software engineering, is a set of conditions or variables under which a tester will determine whether an application, software system or one of its features is working as it was originally established for it to do. The mechanism for determining whether a software program or system has passed or failed such a test is known as a test oracle. A series of tests are performed to find that system is working correctly or not.

- Account Creation: User provides right information that is required by My News web application to create account are show in Figure 10 is tested to ensure that user accounts are being created successfully. Attributes details are given in Table 1.

- Access of user privileges: Users provides right username and password to user their privileges is tested to ensure that users have access of their privileges.

- News Upload: News Any user uploads news after login are show in Figure 11 is tested to ensure that user news being uploaded successfully with required information by My News web application. Attributes details are given in Table 2.

- Verify News: News will be verified by trusted user, sub-administrator or administrator is tested to ensure that news is being displaying after news verification.

- Block News: Any news is disliked by any user will be verified again by trusted user, sub-administrator or administrator to block is tested to ensure to after blocking of news any user has privilege to block news is being blocked.

- Block user: Any user blocked by administrator or sub-administrator cannot upload news are show in Figure 12 is tested to ensure that blocked user cannot upload news and what information provided to blocked user by My News web application. 


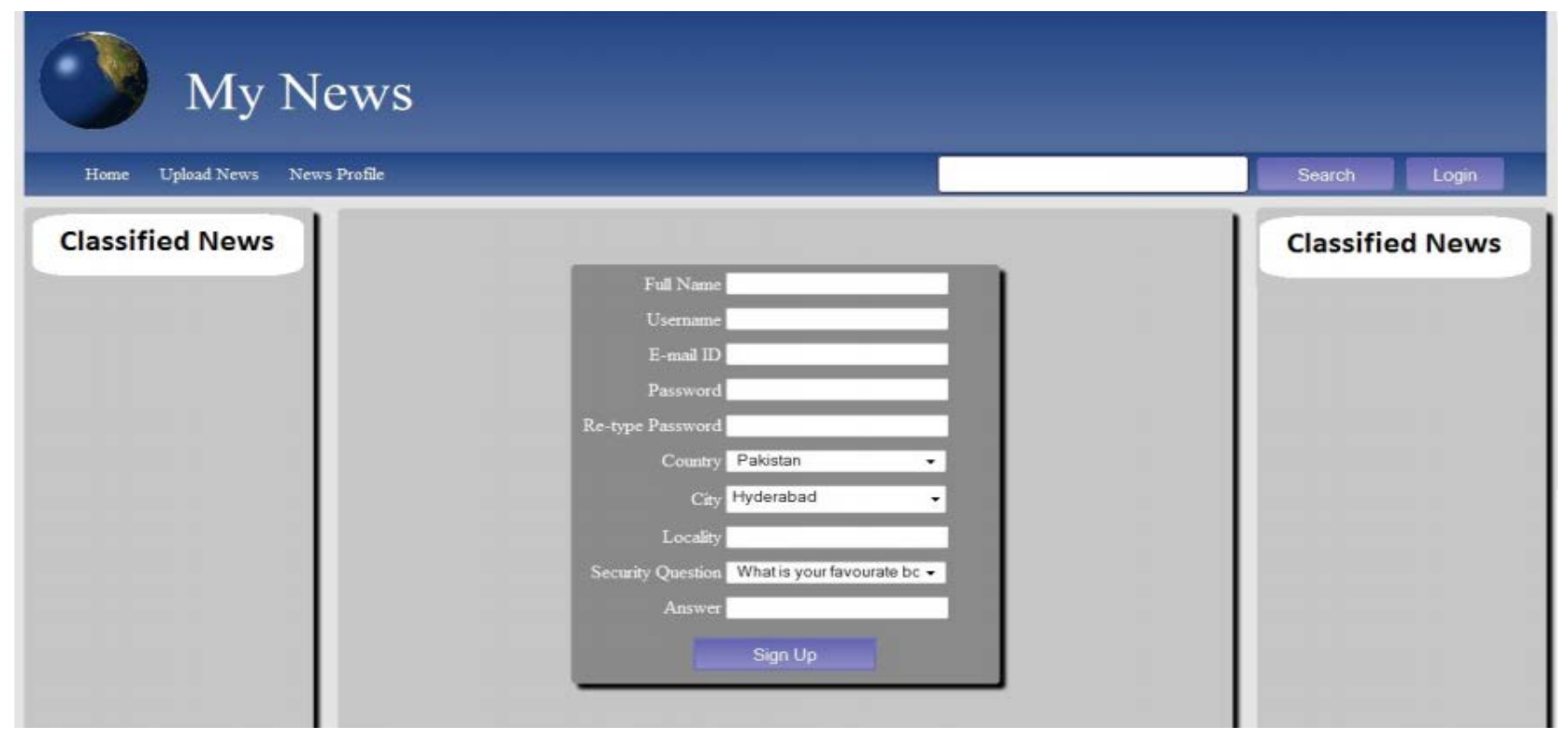

Figure 10. Create account.

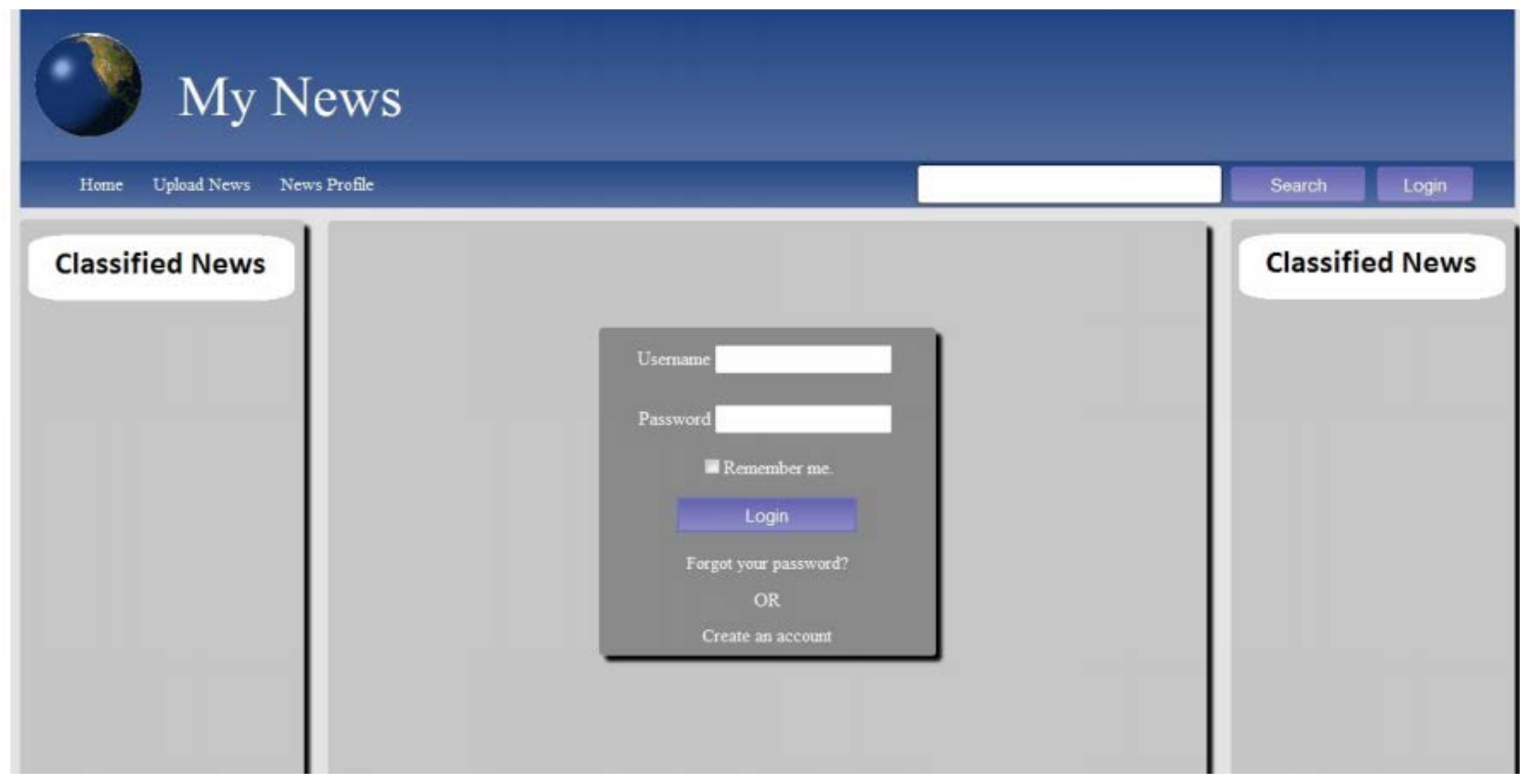

Figure 11. Login page.

- Make user as trusted user: Any user assigned privileges of trusted can use the privileges of trusted user tested to ensure that user can use these privileges of trusted user.

- Make user as sub administrator: Any user assigned privileges of sub-administrator can use the privileges of sub-administrator tested to ensure that user can use these privileges of subadministrator.

\section{Conclusion and Future work}

Our News web application discussed in this article is a very worthwhile web based application that provides news of the world. This application allows users to read according to their news profile. By using this web application user get news of their environment or world to become update from their environment. 


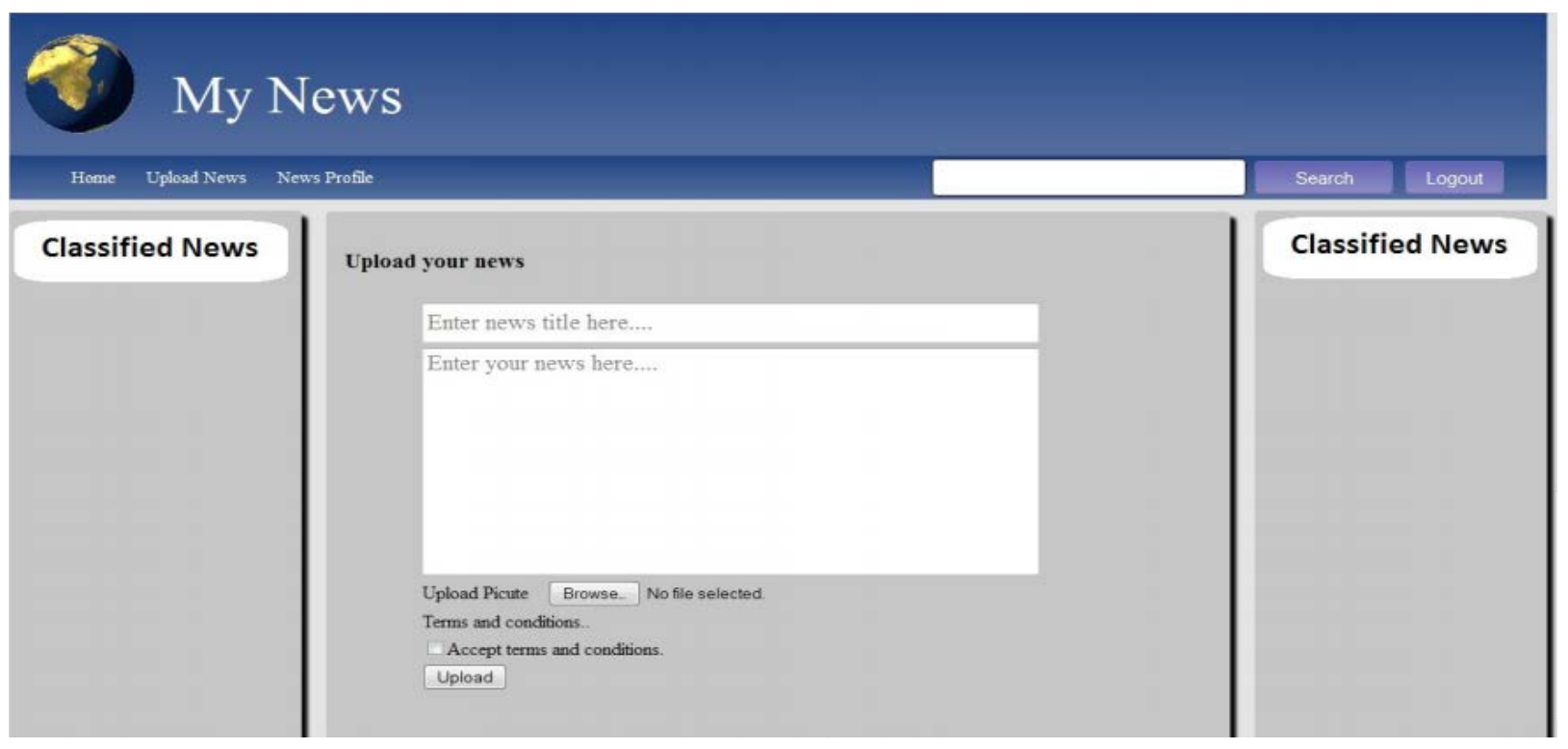

Figure 12. Upload news.

Table 1. Account creation

\begin{tabular}{|l|l|}
\hline Test Case Name & Create Account \\
\hline Pre-Condition & Already registered \\
\hline Propose & The purpose of this test is verify that new account is being correctly \\
\hline & $\begin{array}{l}\text { Full name: Pervizahmednonari } \\
\text { User name: Perviz } \\
\text { Email id: perviz_thul@yahoo.com } \\
\text { Password: itian } \\
\text { Re-type password: itian } \\
\text { Country: Pakistan } \\
\text { Input }\end{array}$ \\
$\begin{array}{ll}\text { City: thul } \\
\text { Locality: mohallanonari } \\
\text { Security question: who is your favorite poet? } \\
\text { Answer: shah abdullatif }\end{array}$ \\
\hline Expected out-put & Display message that you are already registered \\
\hline Actual out-put & Message displayed that you are already registered \\
\hline Test result & No error occur \\
\hline
\end{tabular}

Table 2. News upload

\begin{tabular}{|l|l|}
\hline Test case name & Upload news \\
\hline Pre-condition & Any user expected unregistered user must login to upload news \\
\hline Purpose & The purpose of this test is to verify that news is uploading. \\
\hline Input & $\begin{array}{l}\text { News details: tomorrow is the warsi of shah abdullatif, we are going to arrange program on the occasion of } \\
\text { warsi to remember the shah abdullatifbhittai and inviting all of you to come at bhittai shah to participate in } \\
\text { program. }\end{array}$ \\
\hline Expected output & Message: please fill fields to upload news. \\
\hline Actual output & Registered users page displayed \\
\hline Test result & No error occur \\
\hline
\end{tabular}


Enhancements are the perquisite in any software or application for development. Every existing or legacy system has a proposed enhancement which makes them better and easier to use and more secure. In future News can be enhanced to send news to user's mobile number according to their news profile and also users can discuss or chat online.

\section{Acknowledgment}

We acknowledge, with deep gratitude and appreciation, the inspiration, encouragement, valuable time and guidance given us by Sir Abdul Karim. His timely guidance and useful suggestions helped us during our research work.

\section{References}

1. Ahmed A, Khuhawar SA, Hayat S. FGEHF: Authenticated web based application for human resource management system. Indian Journal of Science and Technology. 2018; 11(43):1-12. https://doi.org/10.17485/ijst/2018/v11i43/131751

2. Ajax: A new approach to web applications. Available from: https://adaptivepath.org/ideas/ajax-new-approach-webapplications/

3. Building Web applications with UML. Available from: https://www.researchgate.net/publication/242595509_ Building_Web_Applications_with_UML

4. Ahmed A, Khuhawar SA, Kimlong N. OPAS: A trusted webbased online property advertising system. Indian Journal of Science and Technology. 2018; 11(40):1-5. https://doi. org/10.17485/ijst/2018/v11i40/131750

5. Analysis and testing of web applications. Available from: https://ieeexplore.ieee.org/document/919078 